\title{
Stressed, Anxious, and Scared: How Early Childhood Educators Feel About Math
}

\author{
Dewi Ochoa Reyes \\ Los Angeles, California, United States \\ Carrie Rothstein-Fisch \\ California State University, Northridge, United States
}

\begin{abstract}
How do early childhood educators feel about math? A 90-minute workshop intended to increase awareness and knowledge of early child mathematics was designed, implemented, and evaluated. Using a convenience sample of 23 graduate students enrolled in a Master of Arts program in early childhood education, the workshop included opportunities for the participants to engage in a variety of hands-on, manipulative activities designed for young children to demonstrate playfulness in math. Data from pre and post workshop questionnaires revealed trends that are likely to underpin early childhood educators' reluctance to engage in math activities with young children. Negative math experiences in school seem to have an enduring impact. While professional development often highlights the importance of math in early childhood and emphasizes the critical roles of early childhood educators to provide a wide range of math opportunities to young children, it may fall short of having a lasting impact as a result of overall negative math feelings. Reawakening educators' playfulness with math is suggested as a novel starting point. Limitations of the study are discussed. Future research is suggested that draws upon the findings of the current study.
\end{abstract}

Keywords: teacher engagement with math, attitudes towards math, preschool math

Early childhood is a critical time for foundational mathematical skills (Clements \& Sarama, 2014; Duncan, et al., 2007; Nguyen, et al.2016). Young children start developing math competencies long before the start of kindergarten, and from that critical foundation, children build an understanding for more complex skills in school (Oppermann, Anders, Hachfeld, 2016). Math standards have been developed to address foundational skills children need to develop. These skills include competencies in: numeracy and operations, measurements and comparisons, geometry and spatial relations, patterning and algebraic thinking, and critical thinking (Clements \&Sarama, 2014; Duncan, et al., 2007; Nguyen, et al.2016). These foundational skills are so important that "achievement in math at school entry 
was the strongest predictor of later success in math, and in some cases reading" (Watts, Duncan, Clements \& Sarama, 2018, p.549). Specifically, number sense and advanced counting skills may be the most predictive skill for later achievement in math (Nguyen, et al., 2016).

Math experiences support children in developing additional cognitive skills as well. These include problem-solving, flexible thinking, and collaborative skills (Duncan, et al., 2007; Kermani \& Aldemir, 2015; Lopes, Grando, \& D'Ambrosio, 2016). Early introduction to math concepts has been found to nurture curiosity for further learning (Kermani \& Aldemir, 2015). Without question, early math skills are very important for young children.

Early childhood educators play a vital role in supporting children's math engagement. Guidance from teachers is key in supporting children's ability to learn and retain math concepts (Carbonneou, Marley \& Selig, 2013; Furman, 2017; Stipek, 2017). When teachers feel confident in their understanding of mathematical concepts and pedagogical content knowledge, they are keener to recognize mathematical thinking in children, add to the children's learning, and properly observe, assess, plan, and scaffold appropriate activities (Clements \& Sarama, 2014; Oppermann, Anders \& Hachfeld, 2016; Stipek, 2017).

However, math anxiety plays an important role in how teachers address mathematical learning in the early years. Teachers' anxiety about their own ability in math and lack of confidence in teaching math skills likely result in avoiding math even at the preschool level. Ultimately, they may share their math anxiety with the children (Geist, 2015; Maloney \& Beilock, 2012).

The Institute of Medicine and National Research Council (IOM) (2015) asserts that there is very little formal education for early childhood educators, weak content knowledge, and little if any preparation in the pedagogy of math. Clements and Sarama (2011) assert how teachers' limited education "from their own early years on, leaves teachers under-prepared for teaching geometry" (p. 136). Furthermore, even when children have been exposed to pre-math activities, they might not understand the connections to school math because they were not provided with opportunities to reflect or discuss these activities to make explicit the potential knowledge from premath activities; especially true if teachers don't understand those connections themselves (Clements \& Sarama, 2014; Ginsburg \& Seo, 1999, Lee, 2014)

The importance of early math development is even more crucial for equity and access embedded in the education of young children. Socioeconomic Status (SES) is widely recognized as a predictor of math ability (Clements \&Sarama, 2014; Duncan, et al., 2007; Nguyen, et al., 2016). Children from low-income families are frequently more challenged, compared to their more privileged peers, and the gap continues to increase during the school years (Duncan, et al., 2007). Similarly, mathematical experiences in the home differ depending on socio-economic status. Families 
with lower SES tend to have a less mathematically rich home environment (Nguyen et al., 2016).

Math-avoidant teachers may dominate the early childhood profession because the early childhood workforce is often drawn from lower SES groups themselves (Geist, 2015). Children's attitudes toward mathematics are clearly influenced by the adults around them (Geist, 2015). How do early childhood educators feel about math? If teachers were more informed about the importance of early math, would they be more inclined to offer it more readily in early childhood setting?

In this study, a workshop titled "Math FUNdamentals," sought answers to these questions. It targeted the potential deficit in understanding of developmentally appropriate goals and strategies for teaching math in daily preschool curriculum. This project explored the emotions of teachers regarding math, their personal experiences with math, and how these feelings and experiences might influence their role in promoting math with young children. The workshop targeted knowledge of mathematical concepts, math vocabulary, and pedagogical strategies.

\section{Method}

\section{Participants}

The participants $(N=23)$ consisted of graduate students at California State University Northridge enrolled in the Master of Arts in Early Childhood Education Program. Of the participants, a total of $21(n=21)$ were in their first semester of graduate program and $2(n=2)$ were their fourth semester of the program. The majority of participants identified as Latinx/ Mexican/ Central American/ Colombian $(n=10,44 \%)$, the remaining participants identified as Caucasian $(n=5,22 \%)$, Asian/ Cambodian/ Japanese/ Korean ( $n=4,17 \%)$, Middle Eastern/ Iranian/ Persian $(n=3,13 \%)$, and African American $(n=1$, $4 \%)$. This was culturally diverse group of participants. Most participants $(n=12,52 \%)$ were $18-25$ years old age range. The majority of participants $(n=1565 \%)$ were bilingual, largely in Spanish $(n=9,40 \%)$ but also in Farsi, Armenian, Cambodian, Korean, Japanese, and Arabic. The majority (91\%) also had teaching experiences in early childhood settings with children from infants- age 8.

\section{Procedure}

The study consisted of a 90-minute workshop during a regular class meeting in a course titled Language and Concept Development that met between 7-10 pm. As the presenter was setting up her materials, the participants received Human Subjects consent forms, along with preworkshop questionnaire and the post-workshop questionnaire. Students could opt out of participating in the study, but $100 \%$ of the students agreed to participate. 
The Workshop began with a PowerPoint ${ }^{\mathrm{TM}}$ presentation focused on how children learn math through guided play. Guided play is defined as a "discovery-learning approach intermediate between didactic instruction and free play" (Weisbert, Hirsh-Pasek \& Golinkoff, 2013, p. 1872). In guided play, teachers arrange the environment and present a learning goal "while allowing children to maintain a large degree of control over their learning" (Weisberg et al., 2013, p. 104). The PowerPoint ${ }^{\mathrm{TM}}$ slide show introduced the five strands of the Math Domain from the California Preschool Learning Foundations (California Department of Education, 2008). This included number sense, algebra, measurement, geometry, and mathematical reasoning. Photographs accompanied each slide of preschool children playing with blocks, measuring, sorting, counting, and creating a variety of shapes came from the presenter's own classroom. For example, a photograph of two boys building a tall structure, alternating brightly colored and natural-colored blocks suggested algebra and functions, specifically classification and patterns. The PowerPoint ${ }^{\mathrm{TM}}$ segment of the workshop lasted about 25 minutes.

After the slide show, participants were invited to engage with math experiences set up around the classroom. These 'centers' replicated how a preschool classroom might be set up with provocations (intentional arrangement of materials to provoke thought and learning) to learn mathematical concepts. For example, two areas provided loose parts to spark geometry experiences, accompanied with books at each of those stations suggesting different shapes and patterns. Magnatiles ${ }^{\mathrm{TM}}$ prompted play with spatial relations and mathematical problem solving. Blocks beckoned for counting and equivalencies. Each station included suggested ways to engage children. The suggestions all included three components: 1) Getting it Started: set up and key terms; 2) Keeping it Going: sparking observations and questions applied to the concepts and continued provocations; and 3) Taking it Further: suggested materials and ideas, deepen children's engagement and challenge their thinking. As the educators engaged the materials, they discussed how the questions and materials provided could be used in their own classrooms with preschool age children.

As the graduate students were experiencing the different areas and activities, the researcher visited each center. She prompted questions that might be raised for including children with special needs and dual language learners. As a result, the process of engagement and exploration took on opportunities for inclusion and bilingualism.

\section{Instrumentation}

Data was collected before and after the workshop. The pre-workshop questionnaire included questions about the graduate students' experiences with math, engaging them to "tell their math stories" as well as describe their math strengths and areas for growth. There were also questions regarding their 
experiences teaching math to young children. Demographic information was also collected about the background of the participants.

After the workshop experience, the participants completed a postworkshop questionnaire. The questions included identifying the most salient parts of the workshop (and why) along with frequency of using similar materials or concepts in their past teaching with what they foresee in their future. They were also asked to identify how they might like to learn more, such as in a TED talk, class, workshop, the professional literature, etc. The pre-workshop questionnaires were coded to match with the post-workshop questionnaires.

\section{Results}

The first question on the pre-workshop questionnaire was, "When you hear the word "math," what feelings come up?" All participants answered with between 1-8 feeling words ( $N=55$ responses). The words most frequently used were stress $(n=5)$, followed by anxiety $(n=4)$. Other words that appeared included: confusion, uneasy, doubt, turmoil, fear, embarrassed, hard, bordeom, helplessness, disappointed, paralized, intimidated, dumb, depression, dislike, tension, worried, nervous, shame, struggle, and dread.

Several students shared more than just feeling words, adding a narrative piece to their answer. One of the responses was a short poem, "Math feels like crushing on a boy that doesn't like you. Math feels like driving in the rain. Math feels like sitting surrounded by mosquitos on the hottest and most humid day of the summer." Another graduate student explained how the earlier struggle with math still affects day-to-day interactions with math.

I get feelings of confusion, boredom, and anxiety. Growing up, I struggled with math, and never considered myself a math person to this day, I make excuses for having other people do calculations for splitting the check at a restaurant. I think of all the times I stared blankly at my math teachers, and felt paralyzed by confusion during homework and tests, to the point of giving up.

To a much lesser degree, some graduate students indicated positive feeling words, such as love, excited, happy, fun, and easy. One student shared, "I have always loved math because I like to figure things out. In math there can only be one answer to a problem, and I like figuring out how to come up with that answer." Overall, the majority of responses indicated of negative feelings $(n=40,73 \%)$, while a quarter of the responses $(n=13,24 \%)$ were of positive feelings, and $2(n=2,3 \%)$ were of neutral feelings. As for the individual participants, $17(74 \%)$ noted negative terms, and 5 responded with positive overall feelings about math $(n=5,22 \%)$ and one was neutral $(4 \%)$. 
Each participant also shared one or more "math stories" related to their math experiences, for a total of $27(N=27)$ stories. The stories ranged from school experiences to daily life with math. Most stories related to experiences with their own teachers. According to one graduate student "I stopped liking math in middle school when a teacher would write the problems on the board and we had the entire class to quietly finish them. He would read Sports Illustrated while I sat there with so many questions and I had been told to figure it out on my own. He would solve the problems at the end and we were supposed to figure out how." Another graduate student added "I had a bad experience sophomore year in high school where I earned all A's and my first $\mathrm{D}$ ever in math and ever since then it has been my worst class. I also always assume that I suck at math before I even attempt it."

One of the participants shared feeling "happy" because of abilities with mental math, having taken abacus classes and even winning math competitions at age 4 . However, this sense of competence was obliterated by teachers who required to "show work," despite the participant's ability to solve problems with mental math alone. For this participant, a teacher's inability to see the student's mental math abilities left a negative impression that lasted into the participant's adulthood. Another reported "I was never good at math. I had to flunk the second grade because my teacher thought I wouldn't do well in math in third grade."

In a different direction, one student described a positive math experience as a way to bridge her challenges with learning English. "English was my second language, I've always preferred math. Math was universal and I could communicate numbers in any language." One of the participants shared that their teacher knew how some of the students were having a hard time with algebra and invited them to learn together after school in a social setting. With this invitation, this teacher changed the student's attitudes about math.

Participants rated their math skills using a Likert scale to describe their skills from very strong to very poor. Despite the negative feeling words and math stories, the majority of participants described their math skills as average $(n=10,44 \%)$. More participants $(n=8,34 \%)$ rated themselves to be above average than below average $(n=5,22)$.

Participants were offered an open-ended set of two columns, one to identify their math strengths and a column for areas of growth potential. Each column had 3 rows of spaces for responses. Some of the responses were one word, others involved a sentence with several categories within. Many of the items were identified as specifically related to math courses. For example, several participants indicated "algebra" $(n=12)$ with 7 educators indicating it as a strength and 5 indicating it as an area of growth. The word "statistics" was mentioned 11 times but virtually split between it being a strength $(n=6$, $13 \%)$ versus an area of growth $(n=5,12 \%)$. (Passing statistics with a grade of $\mathrm{B}$ or better was a prerequisite for entry into the graduate program). "Geometry" was identified 9 times most frequently as an area of in need of 
growth (n-6) compared to strength $(n=3)$. Other topics included daily life math needs (such as splitting the bill, calculating tips, and paying bills) as a strength, but 'mental math' (problem solving in their heads) was more an area for growth $(n=7)$ compared to strength $(n=2)$. Other skills related to mathematical thinking (such as memorization, persistence, estimation, and "understanding why") were listed and almost evenly split (strength: $n=4,9 \%$; areas of growth: $n=3,7 \%$ ).

When prompted to list their preferred methods for encouraging math learning in their classroom, participants shared a wide range of ideas $(N=40)$ with the majority listing counting activities $(n=7,17.5 \%)$ followed by manipulatives $(n=5,12.5 \%)$. Blocks and loose parts were each listed four times $(n=4,10 \%)$ and mentioned separately from other manipulatives or objects and coded separately as well. Among the mention of materials and methods, participants' answers reflected some of their thinking behind teaching math: "Make it fun, like not a lesson," "Strengthen math skills through exploration play and fun activities," "My goal is for the children not to realize it's work," "Exploring and seeing how it's all around us," "Be positive about math, using in my daily language - it could be diaper changing." Other participant responses reflected potentially negative feelings about teaching math, "To make them learn the concepts," "Try to keep them calm and explain the concepts as well as I can," "For children to not be scared of math and to enjoy it."

Participants were asked to rate their confidence in teaching from "I avoid it" to "I make it my daily priority". The majority of participants $(n=11$, $55 \%$ ) indicated that they "integrate it regularly." Though all the participants were graduate students, they had varying degrees involvement in early childhood classroom curriculum. Regardless of what participants reported about their own comfort level with math, the majority $(n=13,59 \%)$ reported integrating math regularly in their curriculum. Out of the 5 participants proclaiming to have the least confidence in their own math abilities, 2 reported engaging in math activities regularly while the other 3 indicated "I do what I can," "not to confident," and "I avoid it."

Immediately following the workshop, participants were prompted to complete their post- workshop questionnaire. The post-workshop questionnaire section focused on learning more about early childhood math, including potential changes in their interest regarding the pedagogy of math as a result of the workshop. In addition, the graduate students were encouraged to share their unanswered questions, and how they might want to learn more.

The post-workshop questionnaire prompted participants to describe the three most important things they learned in the workshop. Participants mentioned a range of ideas regarding their learning. For example, they mentioned learning that math can be fun and playful $(n=10,43 \%)$, learning about the language of mathematics $(n=9,39 \%)$, the use of guided learning $(n=7,30 \%)$, and that math can be engaging and interesting $(n=5,22 \%)$, and 
creative $(n=4,17 \%)$. The graduate students also mentioned learning about the importance of materials used in the workshop, such as loose parts $(n=7,30 \%)$ and building blocks $(n=5,22 \%)$. Several also mentioned the role of social relationships among children $(n=4,17 \%)$ in service to learning about math. Two students $(n=2)$ mentioned learning about how capable young children are, and "we should never underestimate children's abilities." One student shared, "I learned to have fun with math, so I don't have to be fearful," another student mentioned learning "to play with math, so they [children] can have positive associations."

Participants were asked to rate their use of the materials and strategies demonstrated before the workshop, and to rate their potential future use going forward on a scale of $1-5$ (5=daily; 4=frequently; $3=$ =sometimes; $2=$ infrequently; $1=$ never). The overall majority reported that they would increase in the use of the materials and strategies demonstrated in the workshop. The outlier (4\%) responded "As an arts teacher, I won't use math in my curriculum, but I love supporting it if it comes up."

Participants were asked "How might you find opportunities for math throughout the day?" The responses $(N=55)$ to this question varied from single words to paragraphs. There were several themes throughout, the most frequent topic was in the use of math language $(n=9,16 \%)$. Participants also mentioned how math can be found everywhere $(n=8,14 \%)$, can be found within guided activities $(n=7,13 \%$ and in play $(n=4,7 \%)$.

Participants were prompted to choose ways in which they might like to learn more about early childhood math. Overall, the participants preferred to attend workshops $(n=17,40 \%)$. They were also interested in a whole college course $(n=6,14 \%)$, watch a Ted Talk $(n=5,13 \%)$, books/articles $(n=4,9 \%)$ or a webinar $(n=3,7 \%)$. Given the opportunity to rate the overall usefulness of the workshop, the majority of participants indicated it was "super useful" $(n=17,77 \%)$, "useful" $(n=4,18 \%)$ with one other person indicating the workshop was "somewhat" useful $(n=1,5 \%)$.

\section{Discussion}

The results of the current study coincide with previous studies regarding teachers' math anxiety (Bates, Latham, \& Kim, 2013; Celik, 2017; Geist, 2015). Previous research noted that anxiety about math self-confidence can affect teacher's "attitude toward math teaching and anxiety about pedagogical content knowledge" (Peker \& Ulu, 2018, p.252). Teachers' attitudes toward math also inform the activities that they choose to include in their curriculum and how much class time is devoted to it, thereby affecting the children's mathematical development (Celik, 2017; Stipek et al., 2001).

The intensity of emotional words used to respond to the question "When you hear the word "math," what feelings come up?" was staggering. The prompt triggered stress and anxiety most frequently, but the other words 
used were very powerful: confusion, uneasy, doubt, turmoil, fear, embarrassed, hard, bordeom, helplessness, disappointed, paralized, intimidated, dumb, depression, dislike, tension, worried, nervous, shame, struggle, and dread. Ultimately there were 21 different negative words in addition to the stress and anxiety responses. With this much negativity, it is easy to understand teachers' avoidance of math activities.

Interestingly, none of the math stories included playing with blocks, sorting, puzzles, cards, or board games (see Stipek, 2017). This is even more compelling because while the participants were completing the pre-workshop questionnaire, the presenter was setting up the classroom with blocks, sorting loose parts, and Magnatiles ${ }^{\text {TM }}$. Yet even with these materials in plain sight, participants did not think of playing with these items for math learning.

The math stories suggest that educators may be more influenced by the recency of math memories (from formal education) compared to primacy memories (related to early childhood experiences). For example, "I had a bad experience sophomore year in high school where I earned all A's and my first $\mathrm{D}$ ever in math and ever since then it has been my worst class. I also always assume that I suck at math before I even attempt it." From these stories we gather that teachers in every grade must be aware of the impact they have on students' mathematical attitudes and identity.

Despite the largely negative views about math, the majority of participants rated themselves as average or above average in math, and also claimed to integrate math regularly into their programs. This seems counterintuitive. Why is math both anxiety-producing and stress-provoking and yet reported as integrated regularly in programs? The graduate students expressed how they include math in their curriculum, "My goal is for the children not to realize it's work," "To make the learn the concepts," "Try to keep them calm and explain the concepts as well as I can," "For children to not be scared of math and to enjoy it." The undertone of negativity and anxiety that are reflected in these comments can be sensed and imitated by the children (Geist, 2015).

The participants rated the workshop as super useful $(n=17,77 \%)$ or useful $(n=4,18 \%)$. Only one participant indicated it was somewhat useful and that was the same participant who identified as an art teacher. The participants also mentioned that they learned math can be fun, playful, engaging, and interesting. They also indicated that the use of guided learning and materials used in the workshop were helpful. The quote that really hit the mark was "I learned to have fun with math, so I don't have to be fearful."

\section{Limitations}

With a small convenience sample of 23 participants, the results of this research are not generalizable. If anything, the math experiences of graduate students might be more favorable compared to undergraduates or newcomers to the field of early childhood education. Yet, this appears not to be the case. 
Another limitation is the participants' potential bias toward the researcher. The participants understood that their responses would be part of the presenter's thesis project. Therefore, their responses may be more positive than if the workshop was provided in a general professional development setting.

\section{Going Forward}

Reframing negative self-perceptions of math to positive memories of playing with math may be central to the task of increasing teachers' interest and engagement with young children's math. Emphasizing that early childhood educators are not expected to teach advanced math is important (though it seems obvious). Instead, their role is to engage in playful and purposive ways math that is certainly within their existing level of comprehension

In this workshop, early childhood educators were invited to play with the materials intended to trigger the joy of playing with classmates to explore patterns, shapes, and space. This goal was met as the graduate students eagerly engaged with the blocks, loose parts, and tiles. Although it was later in the evening - well past 9:30 pm - it was difficult for the students to put away the materials when it was time to complete the post-workshop questionnaire. In the future, capturing emotion words after playing with math manipulatives would be worthwhile.

What should be the next steps for promoting math in early childhood? There are many elements to consider. A starting point might be to draw on positive math experiences from teachers' personal histories of playing with math for fun. Building on the positive and trying to minimize or mitigate the negative experiences could ideally reawaken math joy. Continuing to showcase research about the importance of math in the early years is important too. While the participants showed interest in learning from a TED talk (passive learning, short time commitment), a series of workshops in which educators have the opportunity to play and engage with materials in the ways they hope for children to do, would do much to reignite their own joy for math.

Constructing professional development based on early childhood educators' relationship orientation is consistent with the Early Math Resources for Teacher Educators (EMTE) goals (Franke, et al, 2021) (https://dreme.stanford.edu/projects/early-math-resources-teacher-educators).

They offer an online repository of resources for teachers of young children. Videos, lesson suggestions, and key vocabulary are included. Their Institutes are geared around teams of early childhood college professors who meet with other regionally based professors to develop communities of shared interest in early childhood math. Regular meetings have been conducted in-person and on zoom (during the pandemic), and many participants continue to attend meetings and Institutes for years. In addition, they promote math learning at 
home by offering family workshops based around sharing a collection of something, such as teacups, sticks, buttons or counting pennies. They model using simple questions such as "What did you see?" "Can you tell me more?" and the use of gestures to represent size, distance, etc.

Math should be integrated in all aspects of the curriculum. Promoting physical development associated with accomplishing math tasks (building a tall tower, counting rungs on ladder while climbing, or counting the beats in a dance) is important. Similarly, with social-emotional and language development, math can be a vehicle for engaging others and communicating with them. What kinds of materials could be added to dramatic play areas? Perhaps conceptualizing math in terms of cognitive development might encourage educators to see more opportunities for engaging with counting, measuring, shapes, and sorting. For example, as toddlers set the table for snack a teacher could engage them in practicing 1:1 correspondence. One plate placed on the table for each chair. Each plate gets one napkin, etc. Cooking projects that require counting, measuring, and weighing along with basic fractions (part/whole) are especially fun (but watch out for food allergies). Finding patterns outside and depicting them symbolically promotes observation, memory, and communication skills derived from nature. While these concepts are addressed generally in curriculum courses for teachers, the focus should emphasize critical ideas and vocabulary in math. Teachers need strong pedagogical content knowledge to make children's implicit math experiences during natural play targeted and explicit.

Finding the math in physical activities, in dramatic play, and in problem solving will be helpful in utilizing more overt math throughout the early childhood curriculum. Ongoing professional development coupled with courses for early childhood educators are important ways to advance early math development. Taking a wholistic approach for children, families, and teachers in playful ways that incorporate the fun in math FUNdamentals will definitely add up!

\section{References}

Bates, A.B., Latham, N. I. \& Kim, J. (2013) Do I have to teach math? Early childhood pre-service teachers' fears of teaching mathematics. Issues in the Undergraduate Mathematics Preparation of School Teachers: The Journal. Vol. 5. ISSN 2165-7874

California Department of Education (2008) California Preschool Learning Foundations (Vol 1). Sacramento: California Department of Education.

Celik, M. (2017) Examination of the relationship between the preschool teachers' attitudes towards mathematics and the mathematical development in 6-year-old preschool children. Journal of Education and Learning. 6(4). Doi:10.5539/jel.v6n4p49 
Clements, D. H. \& Sarama, J. (2011) Early childhood teacher education: The case of geometry. Journal of Mathematics Teacher Education (14) 133-148. DOI: 10.1007/s10857-011-9173-0

Clements, D.H., \& Sarama, J. (2014) Learning and teaching early math: The learning trajectories approach. New York, NY: Routledge.

Duncan, G. J., Dowsett, C. J., Claessens, A., Magnuson, K., Huston, A. C., Klebanov, P., Pagani, L. S., Feinstein, L., Engel, M., Brooks-Gunn, J., Sexton, H., Duckworth, K. \& Japel, C. (2007) School readiness and later achievement. Developmental Psychology 43(6) p. 1428-1446 DOI: 10.1037/0012-1649.43.6.1428

Franke, M., Ginsberg, H. Platas, L, \& Stipek, D. (2021, April 4). Early math resource for teacher education.

https://dreme.stanford.edu/projects/early-math-resources-teachereducators

Furman, C. E. (2017). Making sense with manipulatives: Developing mathematical experiences for early childhood teachers. Education and Culture 33(2) 67-86. https://docs.lib.purdue.edu/eandc/vol33/iss2/art5

Kermani, H. \& Aldemir, J. (2015) Preparing children for success: integrating science, math, and technology in early childhood classroom. Early Child Development and Care. Vol 185(9) p. 1504-1527. DOI: 10.1080/03004430.2015.1007371

Lopes, C.E., Grando, R.C. \& D’Ambrosio, B.S. Experiences Situating Mathematical Problem Solving at the Core of Early Childhood Classrooms. Early Childhood Educ J 45, 251-259 (2017). https://doi.org/10.1007/s10643-016-0775-0

Nguyen, T., Watts, T. W., Duncan, G. J., Clements, D. H., Sarama, J. S., Wolfe, C., \& Spitler, M. E. (2016) Which preschool mathematics competencies are most predictive of fifth grade achievement? Early Childhood Research Quarterly, 36, 550-560. http://dx.doi.org/10.1016/j.ecresq.2016.02.003

Oppermann, E., Anders, Y., Hachfeld. (2016). The influence of preschool teachers content knowledge and mathematical ability beliefs on their sensitivity to mathematics in children's play. Teaching and Teacher Education.58 174-184.

Peker, M. \& Ulu, M. (2018) The effect of pre-service mathematics teachers' beliefs about mathematics teaching-learning on their mathematics teaching anxiety. International Journal of Instruction. 11 (3). p. 249264. https://doi.org/10.12973/iji.2018.11318a

Stipek, D. (2017) Playful math instruction in the context of standards and accountability. Young Children. Vol. 7(3)

Watts, T. W., Duncan, G. J., Clements, D. H., Sarama, J. (2018) What is the long-run impact of learning mathematics during preschool? Child Development 89(2) p. 539-555. DOI:10.1111/cdev.12713 


\section{Author Note:}

Dewi Ochoa Reyes, MA

Los Angeles California

Carrie Rothstein-Fisch, PhD.

California State University, Northridge. Professor and Co-coordinator, Master of Arts in Early Childhood Education

This research was conducted as part of the first author's master's thesis. The second author served as her thesis chair.

Correspondence concerning this article should be addressed to Dr. Carrie Rothstein-Fisch

Carrie.rothstein-fisch@csun.edu

We thank the editors for their helpful suggestions and the graduate students who participated in this research. 